\title{
Workplace bullying in healthcare facilities: Role of caste and reservation
}

\author{
MRINAL PRAKASH BARUA, ANITA VERMA
}

\begin{abstract}
Medical education in India is afflicted with a culture of abuse and workplace bullying of junior doctors and medical students. This abuse is often rationalised on grounds of so-called high standards of healthcare delivery. Poor standards of work sometimes get attributed to caste-based reservations vs admissions based on 'merit-due to elitist mindsets that prevail in our society. The cycle of abuse that goes on in medical colleges is incorporated (though not in a legal sense) into its hierarchical structure. Focussing attention only on casteism tends to overshadow the bullying of doctors and medical students by their senior colleagues at the workplace.
\end{abstract}

Keywords: casteism, reservation' quotas, authoritarian work culture

\section{Background}

What killed Dr Payal Tadvi (1)? In May 2019, a series of events that followed the death by suicide in Mumbai of the young resident doctor from a tribal Muslim community, three women doctors who were her seniors were taken into custody and their trial is ongoing. The media, at the time, were filled with reports of a torrent of casteist innuendo against her that may have precipitated the tragedy. The impact of caste in India is overwhelming.

\section{Authoritarianism in healthcare}

Teaching by humiliation and mistreatment is almost standard operating protocol for medical education throughout the world (2-5). An arbitrary code of strict obedience, that despises personal freedom, is amalgamated within the hierarchical structure of healthcare. Those unable to fit in are

Authors: Mrinal Prakash Barua (corresponding author - mrinalbarua@ gmail.com), Additional Professor, Department of Anatomy, All India Institute of Medical Sciences, Rishikesh, Uttarakhand, INDIA; Anita Verma (anitav. psyc@aiimsrishikesh.edu.in), Senior Resident, Department of Psychiatry, All India Institute of Medical Sciences, Rishikesh, Uttarakhand INDIA.

To cite: Barua MP, Verma A. Workplace bullying in healthcare: Role of reservation and caste. Indian J Med Ethics. 2021 Jan-Mar; 6(1) NS: 44-46. 2020. DOI:10.20529/IJME.2020.107.

Published online first on October 30, 2020

Manuscript Editor: Rakhi Ghoshal

Peer Reviewer: Monty Khajanchi

(c) Indian Journal of Medical Ethics 2020 surreptitiously sidelined or reprimanded for "poor work". This authoritarian system is self-perpetuating and reminiscent of lemming behaviour. As victims often end up becoming perpetrators themselves, the cycle of abuse continues commonly seen in the way ragging is perpetuated. Affective relations between senior and junior doctors are also patterned on the established hierarchical structure of medicine. Here in India, we consider such unprofessional behaviour as an occupational hazard rather than an offence, because the government healthcare system is negligent about addressing such matters. In untenable situations, a standard administrative approach is to charge a few individuals in the proximate responsibility chain and move on with the pitiless work culture until another catastrophe strikes.

\section{Betraying rationality}

The misplaced adoration of the healthcare profession as "noble" (6), an apparently merit-based selection process for college admissions (7), the rising aspirations of doctors to become specialists, and the incessant volume of work in public healthcare organisations have created artificial, arbitrary and unnecessary barriers to postgraduate medical education. Demands for unrealistically high standards of healthcare performance in our country, where the healthcare budget is just a minor fraction of GDP (8), are inordinate and impracticable. A reality check is needed for developing pragmatic approaches to patient care (9). An interesting phenomenon in this regard is related to the ever-increasing workload of doctors, in terms of number of patients (10). A high volume of patients, especially in the medical college and hospitals, creates fertile ground for abuse. In such scenarios, senior doctors tyrannise over junior doctors, particularly over postgraduate students, routinely, citing western standards of patient care, when in the Indian reality basic infrastructure is often missing.

\section{The casteism-reservation intersection}

The problem of casteism in medical colleges is partly fueled by reservation in entrance examinations (11). We live in a purportedly equal and democratic society but there are profound undertones of equality defying meritocracy in people's minds. While discriminatory behaviour is not part of any formal system, there are doctors who are disapproving of reservation policies. In our experience, many doctors belonging to the "general" category do think of doctors entering postgraduate medical education through a reserved quota of seats as "undeserving". This happens because the 
selection process appears meritocratic in the sense that there is a ranking of selected candidates based on normative assessment. Normative assessments do not determine if candidates have met learning standards or acquired specific knowledge. Because of poor understanding of the purpose of the exam, an idea percolates amongst doctors that if a low ranking candidate is getting selected on a quota seat, he or she will not be as intelligent as themselves. This creates a background where substandard performance at work sometimes gets attributed to caste. As such, all trainee doctors get reprimanded for substandard work, irrespective of caste. The problems of living in a meritocratic system is that privileged individuals resist acknowledging their privileges because doing so would require them to acknowledge that whatever success they have achieved did not result solely from their own efforts. We are not sure whether a meritocratic system is constructive, even in principle, for any society $(12$, 13).

However, general category doctors are also upset when candidates belonging to Scheduled Castes (SC)/Scheduled Tribes (ST )/Other Backward Classes (OBC) 1 are able to secure "open seats". The total number of seats open to the general candidates are reduced by reservation of seats for the deprived groups. Scheduled Caste/Scheduled Tribe/Other Backward Classes candidates getting selected for open seats is a good thing because it means reservation seems to be serving its greater purpose of representation. However, general category candidates think of "open" seats as their own quota of seats, which is fundamentally wrong, and expect SC/ST/OBC candidates to restrict themselves to their "own" quotas, even if they qualify for an open seat. If an SC/ST/OBC candidate switches to an open seat, then one more SC/ST/OBC candidate gets a chance to get the privilege of reservation. As more SC/ ST/OBC candidates are securing open seats on merit, the frustrations of general category candidates are rising. The selection process with reservation embedded within it, has created palpable conflicts amongst doctors with significant spillover into the arena of medical education and clinical practice.

It is not critical to healthcare that only individuals with very high marks should have access to medical education. That would be like a eugenics movement. High intelligence may be an asset for ambitious individuals but medical education is about having uniform minimum standards as prescribed by the Medical Council of India. This is probably why there is no reservation in medical exit exams. There are fixed benchmarks for earning an MBBS or MD degree, irrespective of social class. Despite knowing this, some doctors are unable to shed their resentment towards all doctors admitted through a quota. Another potential source for development of such mind-sets could be coaching centres for undergraduate/postgraduate medical entrance examinations which magnify the amplitude of "competition" to unforgiving levels.

\section{The greater purpose of reservation}

Despite being a rational and progressive policy for social equity, quota-based reservation is facing challenges because it is often poorly understood by most people. Reservation is a social privilege. Some general category doctors believe reservation to be a set of circumstances that SC/ST/ OBC doctors are exploiting for career advancement without any reasonable basis and that their thinking is individualistic and defies any social purpose. On the other hand, some SC/ST/ $\mathrm{OBC}$ doctors tend to be reluctant to acknowledge the "social privilege" because that might make them look less intelligent or deserving.

Reservation has the larger purpose of diverse representation in the services. Though reservation appears to be a static entity in terms of quota percentage, the heterogeneous nature of the SC/ST/OBC population in India makes it a sublime policy tool. Though Article 46 of the Indian Constitution mandates that the state will protect "weaker" sections from social injustice, the basis for reservation is made clear in Article 16(4) of the Constitution which states that "nothing in this article shall prevent the State from making any provision for the reservation of appointments or posts in favor of any backward class of citizens which, in the opinion of the State, is not adequately represented in the services under the State". It clarifies that reservation is a social privilege for certain sections of society (that comes with a constitutional duty to represent) rather than a chance for personal advancement, progress or profit. Proportionality in political representation and civil service appointments along with a minority veto is central to upholding democracy in a massively heterogeneous state (14).

\section{Understanding discrimination}

"Discrimination" pops up frequently in "media trials" involving matters similar to $\mathrm{Dr}$ Tadvi's case. A negative connotation and its indiscriminate use makes discrimination a powerful expression. There are different meanings to this word when used in different contexts. In a political context it refers to prejudice against people and refusal to give them their rights. What people generally mean by discrimination refers to treatment of a person or a group of people differently, that is worse than the way people are usually treated. It is unconstitutional for people in government services to discriminate against certain classes or groups. While aberrations are punishable under the Indian Penal Code; in reality, people engage in biased interpersonal behaviour that may be subtle enough to circumvent detection but quite effective in causing physical and mental disturbance.

\section{Suicides by doctors}

Suicide rates among doctors have been reported as remarkably higher than among the general population (15). Suicide is a highly complex and multifaceted phenomenon, with many contributing and facilitating variables. Existing 
evidence $(16,17)$ supports the theory that the need to belong is a powerful, fundamental, and extremely pervasive motivation. The unmet need for connectedness and social competence results in psychologically painful mental states and these are proposed to be the most proximate mental states that precede thoughts of suicide. Stressful life events, mental disorders, and other risk factors for suicide are relatively more distal in the causal chain of risk factors for suicide. It is important to note that the proximate causes are amenable to therapeutic change but that would require amicable work environments where doctors are not biased against other doctors. While it is unconstitutional for doctors to indulge in biased behaviour towards fellow doctors belonging to $\mathrm{SC} / \mathrm{ST} / \mathrm{OBC}$, at the same time doctors from SC/ ST/OBC must understand that they have a greater responsibility of representing their communities in services and must resist yielding to adverse interpersonal dynamics. Treating the beneficiaries of reservations as liabilities instead of assets is an abominable act.

\section{Conclusion}

A written code of professional conduct may be laid down for all healthcare workers and should include protocols for prevention of disruptive behaviours by doctors towards other doctors and medical students. Narcissism of individuals should be kept in check by healthcare organisations (18). Addressing the mental health needs of doctors and other healthcare professionals as a policy matter could be a positive step towards ensuring patient safety as well as protecting the lives of doctors.

\section{Competing interests and funding: None declared.}

Note

Articles 341 and 342 of the Constitution of India define who would be Scheduled Castes and Scheduled Tribes with respect to any State or Union Territory; Other Backward Classes means such socially and educationally backward classes of citizens other than the Scheduled Castes and the Scheduled Tribes as may be specified by Central Government

\section{References}

1. Satheesh S. Payal Tadvi suicide case: The death of a doctor. Live Mint. 2019 Jun 7[cited 2020 Jul 30]. Available from: https://www.livemint. $\mathrm{com} / \mathrm{mint}$-lounge/features/payal-tadvi-suicide-case-the-death-of-adoctor-1559891147950.html.

2. Scott KM, Caldwell PH, Barnes EH, Barrett J. "Teaching by humiliation” and mistreatment of medical students in clinical rotations: a pilot study. Med J Aust. 2015 Aug 17; 203(4):185e.1-6.

3. Barrett J, Scott KM. Acknowledging medical students' reports of intimidation and humiliation by their teachers in hospitals. $J$ Paediatr Child Health. 2018 Jan; 54(1):69-73. Doi: 10.1111/jpc.13656.

4. Hoskison K, Beasley BW. A conversation about the role of humiliation in teaching: the ugly, the bad, and the good.Acad Med.2019 Aug; 94(8):1078-80. Doi: 10.1097/ACM.0000000000002594.

5. Cope JF." "Toxic" bedside teaching: patient impact. Adv Med Educ Pract. 2018 Sep 18; 9: 673-5. doi:10.2147/AMEP.S180801

6. Kumar AA. Medical profession: the other side of the coin. Hindu. 2012 Sep 18[cited 2020 Jul 30]. Available from: https://www.thehindu.com/ opinion/open-page/medical-profession-the-other-side-of-the-coin/ article2907840.ece

7. National Board of Examinations. NEET-PG 2019. Public Notice. 2019 Jan 31[cited 2020 Jul 30]. Available from: https://drive.google.com/ file/d/1wNEmtbYF4MIzH eWFzUahOMZec-KloRw/view

8. Dey S. India's health spend just over 1\% of GDP. Times of India. 2018 Jun20 [cited 2020 Jul 29]. Available from: https:// timesofindia.indiatimes. com/business/india-business/indias-healthspend-just-over-1-of-gdp/articleshow/64655804.cms

9. India State Level Disease Burden Coordinators. Nations within a nation: variations in epidemiological transition across states of India, 1990-2016 in the Global Burden of Disease Study. Lancet. 2017 Dec 2[cited 2019

Sep 18]; 390(10111):2437-60. Available from: https://www.thelancet. com/ journals/lancet/article/PIIS0140-6736(17)32804-0/fulltext

10. Gupta AK, Talati S, Bhattacharya S. Singh AK. Health system strengthening-focusing on referrals: An analysis from India. JOJ Nurs Health Care. 2017 Jun [cited 2020 Jul 30]; 2(4): 555592. Doi:10.19080/ JOJNHC.2017.02.5. Available from: https://juniperpublishers.com/ jojnhc/pdf/JOJNHC.MS.ID.555592.pdf

11. Students of the Seth GS Medical College. Reservation of seats in medical colleges on the basis of caste. Views pro and con. Indian J Med Ethics. 1994 Oct-Dec; 2(4):10-11. [cited 2020 Jul 31]. Available from https://ijme. in/articles/reservation-of-seats-in-medicalcolleges-on-the-basis-of- caste-views-pro-and-con/?galley=html

12. Teklu TA. Meritocracy and inequality: moral considerations. Palgrave Commun. 2018 Jan 9 [cited 2020 Jul 30]; 4(1):1-9. Available from: https:// www.nature.com/articles/s41599-017-0059-3

13. Manstead ASR. The psychology of social class: How socioeconomic status impacts thought, feelings, and behaviour. Br J Soc Psychol. 2018; 57(2):267-91. doi:10.1111/bjso.12251

14. Lijphart A. The puzzle of Indian democracy: A consociational interpretation. Am Polit Sci Rev. 1996 Jun [cited 2020 Jul 30]; 90(2):25868. Doi: 10.2307/2082883. Available from: https:// www.cambridge.org/ core/journals/american-political-sciencereview/ar ticle/puzzle-of- indian-democracy-a-consociationalinterpretation/282CAD11CE716873F5EFD96886BEF5D7

15. Ventriglio A, Watson C, Bhugra D. Suicide among doctors: A narrative review. Indian J Psychiatry. 2020 Mar-Apr; 62(2):114-120. doi:10.4103/ psychiatry.IndianJPsychiatry_767_19

16. Chu C, Buchman-Schmitt JM, Stanley IH, Hom MA, Tucker RP, Hagan $\mathrm{CR}$, et al. The interpersonal theory of suicide: A systematic review and meta-analysis of a decade of cross-national research. Psychol Bull. 2017 Dec;143(12):1313-45. Doi:10.1037/bul0000123.

17. Van Orden KA, Cukrowicz KC,Witte TK, Joiner TE.Thwarted belongingness and perceived burdensomeness: construct validity and psychometric properties of the Interpersonal Needs Questionnaire. Psychol Assess. 2012 Mar; 24(1):197-215. Doi:10.1037/ a0025358.

18. Kumar V D. Multiple faces of narcissistic leadership in medical education. J Adv Med Educ Prof. 2019 Apr;7(2):103-5. Available from:doi:10.30476/ JAMP.2019.44705 